\title{
SIMULATING A NEW BUSINESS MODEL: A DYNAMIC BUSINESS MODEL APPROACH STUDY ON PT. AMM POULTRY PARTNERSHIP COMPANY
}

\author{
Yudha Fendria*, Raharja Sam'un Djaja, Rizal Muhammad \\ Department of Business Administration, University of Padjadjaran, Bandung, Indonesia \\ *E-mail: fendria.yudha@unpad.ac.id
}

\begin{abstract}
Recent study show that the reconfiguration and reconstruction of new business models begin with the demands of changes or the addition of the company's value proposition that offered to consumers. The reconstruction and reconfiguration of the business model are known as business model innovation. In this study, the author conducted a simulation of the configuration of the new business model from PT. The AMM Poultry Partnership Company as a result of changes in the value proposition of the company using the steps to form a new business model includes identifying the new value proposition offered, profit formulation, and key resources and key process business models which are then simulated using a system dynamic approach that adopts the concept of dynamic business models. Based on the results with simulations over a period of 12 months, PT. AMM cumulatively had an increase in financial resources of $120 \%$ and an increase in the number of breeders' population of 133928 to 144375 at the end of the simulation period. The optimal configuration of all business model components for the company in the simulation is seen in May - December with a positive cumulative increase. If it reflects the vision of a company that wants balanced profits for both the company and the farmer. The appropriate configuration is in August, September and November of the simulation month. This is because the farmer reaches the maximum profit value and the company has a positive profit.
\end{abstract}

\section{KEY WORDS}

Business model, innovation, dynamic business model, public service.

In Indonesia, the development of the SME production index from 20152018 shows 5 sectors with the highest production index from 25 industrial sectors including the Printing and Reproduction of Recording Media, Computers, Electronic and Optical Goods, Chemicals and Chemicals, Food, Paper, and Paper Products. The highest value-added according to data in 2015 is in the food industry sector wherein 2015 the industry at the micro scale has value added of IDR 48,546,016 and on a small scale IDR 30,037,722. This value-added shows the level of profit obtained from the difference between input and production output. The high production index and value-added of the food sector are followed by growth in the supporting sectors including the livestock industry. The commodities with the highest demand in the livestock industry in 2015 and 2016 were in broiler commodities (Indonesian Central Bureau of Statistics, 2019).

PT. Anjawani Mitra Madani (AMM) is one of the companies engaged in broiler cultivation with a partnership system that started its business in 2016 with a legal entity CV (Commanditer Venoscape) and in 2018 switched the status of a business legal entity to a Limited Liability Company (PT) this is a feature of the progress of the AMM itself due to existing market conditions. At the beginning of its establishment, AMM started its business by targeting small breeders with a capacity of 1000-15000 chickens in 1 production period or 21-31 days as its business partners, where farmers with this capacity are not targeted by large poultry partnerships targeting business partners with production capacity chickens more than 30,000 chickens with a closed house system. The new value proposition from PT. AMM is to provide high profits compared to similar companies by offering the highest contract price for chicken purchases in a period and an excess margin percentage bonus if the market price is higher than the price of the purchase contract. 
Recent studies show that the process of adding and changing the value proposition demands a change in the overall business model with the aim of increasing the sustainability of its business (Jhonson, 2018). The change in business model is generally known as business model innovation, where the process begins with analyzing the potential and processes of existing business models, simulating them until finally implemented (Geissdoerfer, Savaget, \& Evans, The Cambridge Business Model Innovation Process, 2017), (Zhao, Bon-Gang Hwang, \& Lu, 2018), (Z. Lindgardt,, M. Reeves, G. Stalk, \& MS Deimler, 2009) (Chesbrough H., Business model innovation: it's not just about technology anymore, 2007). In this study, the author will simulate the new business model of PT. AMM with identifying new value propositions, profit formulation, and key resource and key process of business and describe the interrelation in a dynamic system model by adopting the principles of the Dynamic business model from cosen and noto that modeled business component interrelations models in system dynamic (Cosenz \& Noto, 2018). System dynamic is recommended for analyzing and modeling business strategies (Forester, 1997), (Sterman, 2001), (Davis, Eisenhardt, \& Bingham, 2007), (Morecroft, 2015),

\section{LITERATURE REVIEW}

Reconstruction process and reconfiguration of business models with the aim of increasing performance, competitive position and sustainability of this business called business model innovation (Geissdoerfer, Savaget, \& Evans, The Cambridge Business Model Innovation Process, 2017 ), (Zhao, Bon-GangHwang, \& Lu, 2018), (Z. Lindgardt,, M. Reeves, G. Stalk, \& MS Deimler, 2009) (Chesbrough H., Business model innovation: it's not just about technology anymore , 2007). The demand for changes in business models occurs when the value proposition offered to consumers' changes or is added to as a trigger for changes in the overall business model components (Jhonson, 2018).

Business models, in general, are representations of organizational processes in producing goods and services offered to get a return in the form of profits or benefits by satisfying consumers based on the ability of their resources. The definition of the majority of business models emphasizes the relationship of part or all aspects including the product, management infrastructure, customer interface, and financial aspects, while others emphasize the implementation of business function strategies. Aspects in the business model environment consist of 7 building blocks including key partners, strategic resources, value propositions and key performance, key processes, customer segments, cost structures, and revenue streams, and then called the business model canvas that describes the relationship of the product, consumers, and networks that connect products and consumers (Geissdoerfer, Vladimirova, \& Evans, Sustainable business innovation model: A review, 2018), (Bieger \& S. Reinhold, 2011), (G. George \& AJ Bock, 2011), (L. Massa, C. Tucci, \& A. Afuah, A critical assessment of business model research, 2017) (Timmers, 1998), (Richardson, 2008) (Masanell \& JE Ricart, 2010) "(C. Zott \& R. Amit) (M. Geissdoerfer, NMP Bocken, \& EJ Hultink, Design thinking to enhance the sustainable business modeling process, 2016) Jhonson et al. (Jhonson, 2018) simplifies the components of the business model into a four building box concept among them consists of da value proposition, profit formulation, key process, and key resource. To find out the ideal change of business model for the company, a study is needed to compare the expected conditions with the existing reality, analyze the existing business model potential, determine a new design of the value proposition to offer to consumers, profit formulation, key resources and the right key process (Geissdoerfer, Savaget, \& Evans, The Cambridge Business Model Innovation Process, 2017) (Jhonson, 2018).

Dynamic business model (DBM) is an interrelation construction of business model components depicted in a dynamic system model that allows adjustment of the framework structure of the company's strategy while DBM itself is depicted in Figure 1. The business model component is modeled interconnected between one another. The construction of DBM itself can be configured according to the strategies used (Cosenz \& Noto, 2018). 


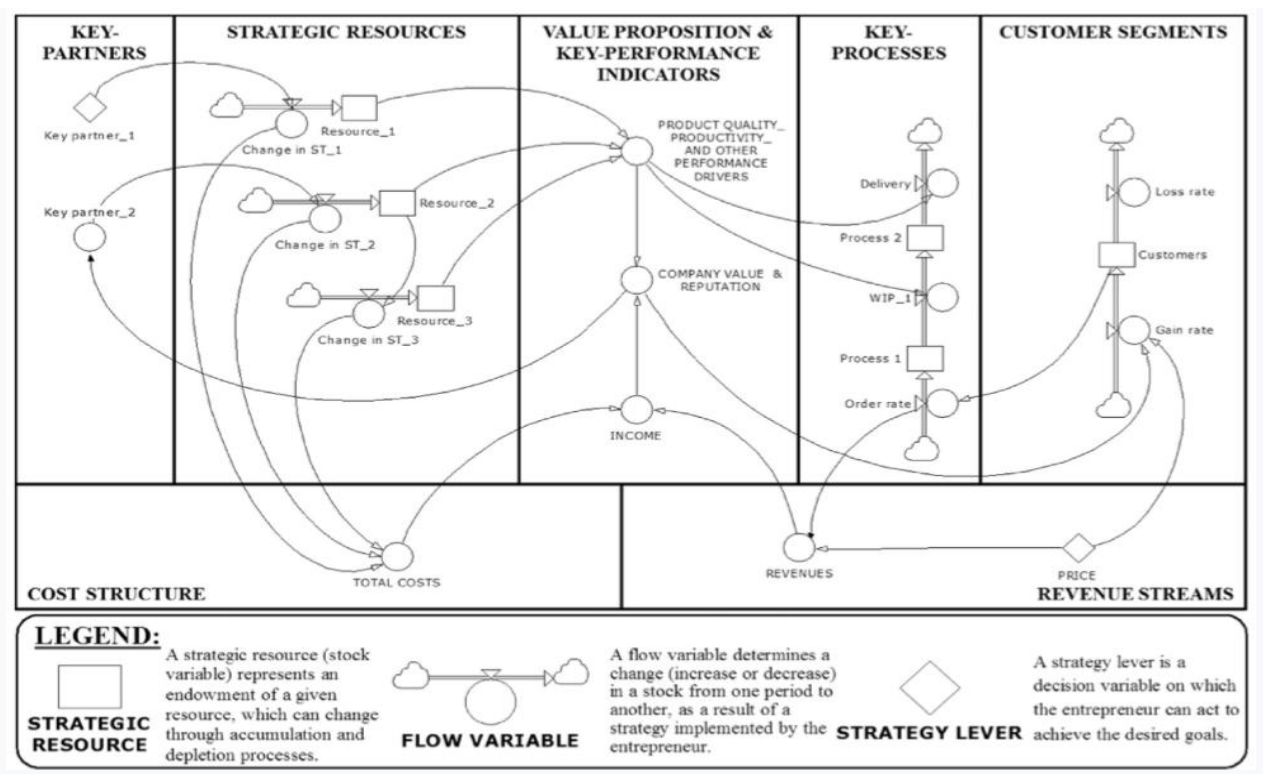

Figure 1 - DBM framework Structure (Cosenz \& Noto, 2018)

\section{METHODS OF RESEARCH}

The research method used in this study is the mix methods that combine quantitative and qualitative approaches. Mixed research is a research approach that combines qualitative and quantitative research (John. W. Creswell, 2010, p. 5). The research design used is sequential mixed methods with a sequential exploratory approach which is a method of combining data found from one method to another. Where this approach begins with collecting and analyzing qualitative data then followed by the collection and analysis of quantitative data that is built on the initial results of a qualitative approach. Analysis tools used as a system dynamic analysis tool using Powersim software version 10.14.

\section{RESULTS AND DISCUSSION}

PT AMM's New Value proposition is offered compared to other poultry partnerships, which are to provide balanced profits for small breeders partners by offering purchase contract prices in accordance with market price fluctuations but above the farmers' production costs so that farmers are not harmed and give positive bonuses from the sale price difference a contract of $30 \%$ is expected to increase the trust of farmers and increase the number of farmers' ability to increase their livestock population. The number of breeders production population is assessed by PT. AMM can increase economies of scale so that production costs can be reduced lower so that market price fluctuations do not significantly affect the profits obtained by companies and farmers.

New Profit Formulation PT AMM is formulated by comparing the value of the sale of livestock production facilities (drugs, feed, DOC seeds) and the production of broiler breeders. DOC sales depend on the number of partners and capacity of the enclosure. The margin of the difference between the purchase and sale of sapronak and the difference between the sale of chicken and the purchase of the contract price of the farmer that is accumulated is the total of the company's profits.

New Key resources \& Key Process to fulfill the value proposition offered by PT. AMM is to offer the best products for livestock production so that it can produce high production productivity as well as resources that support chicken production activities. The key resources of the company include superior DOC and Feed. The increase in breeder population will increase feed requirements and DOC needs while The process of production activities includes on-farm activities to off-farm on-farm processes including stages of preparation of drums and entry of seeds to the temporary maintenance process off-farm 
process is a sorting process based on chicken weight to determine at one year there are 8 cycles of livestock with this because in certain months there is a resting phase of the cage this phase is divided into 2 categories, the first is the resting phase to clean the cage to keep the disease seeds away while the rest phase is the phase for avoiding crop failure because the season is not ideal for raising livestock.

Table 1 - Loops and Dynamics New DBM PT. AMM

\begin{tabular}{|c|c|}
\hline Loop & Dynamic \\
\hline $\begin{array}{l}\text { R1 FinancialResources }=>\text { MarginBonus \& BreederRevenue }=>\text { breederprofit }=> \\
\text { chickenpopulation }=>\text { Chick in }=>\text { DOC }=>\text { TotalFeed }=>\text { FeedRevenue }=> \\
\text { FeedMargin => financial resources }\end{array}$ & \multirow{3}{*}{$\begin{array}{l}\text { Increasing the number of breeders } \\
\text { population due to the ability of companies } \\
\text { to provide margin margin bonuses can } \\
\text { increase the amount of DOC, Feed and } \\
\text { chicken production needs so that it } \\
\text { increases financial }\end{array}$} \\
\hline $\begin{array}{l}\text { R2 FinancialResources }=>\text { MarginBonus \& BreederRevenue }=>\text { breederprofit }=> \\
\text { chickenpopulation }=>\text { Chick in }=>\text { DOC }=>\text { RevenueDOC }=>\text { MarginDOC }=> \\
\text { financial resources }\end{array}$ & \\
\hline $\begin{array}{l}\text { R3 FinancialResources => MarginBonus \& BreederRevenue => breederprofit => } \\
\text { chickenpopulation =>Chick in => DOC companyrevenue (chicken) } \\
\text { ChickenMargin => financial resources }\end{array}$ & \\
\hline $\begin{array}{l}\text { B1 FinancialResources }=>\text { MarginBonus \& BreederRevenue }=>\text { breederprofit }=> \\
\text { chickenpopulation }=>\text { Chick in }=>\text { DOC }=>\text { TotalFeed }=>\text { FeedOrder }=>\text { FeedCost } \\
=>\text { FinancialResources }\end{array}$ & \multirow{3}{*}{$\begin{array}{l}\text { Increasing the number of breeders' } \\
\text { population due to the strengthening of } \\
\text { financial resources and breeders' } \\
\text { population causes the cost of feed needs, } \\
\text { DOC, the total harvest weight increases } \\
\text { and becomes a counterweight to the } \\
\text { company's income. }\end{array}$} \\
\hline $\begin{array}{l}\text { B2 FinancialResources => MarginBonus \& BreederRevenue => breederprofit => } \\
\text { chickenpopulation =>Chick in => DOC DOCCost => FinancialResources }\end{array}$ & \\
\hline $\begin{array}{l}\text { B2 FinancialResources }=>\text { MarginBonus \& BreederRevenue }=>\text { breederprofit }=> \\
\text { chickenpopulation }=>\text { Chick in }=>\text { MarginBonus }=>\text { FinancialResources }\end{array}$ & \\
\hline
\end{tabular}

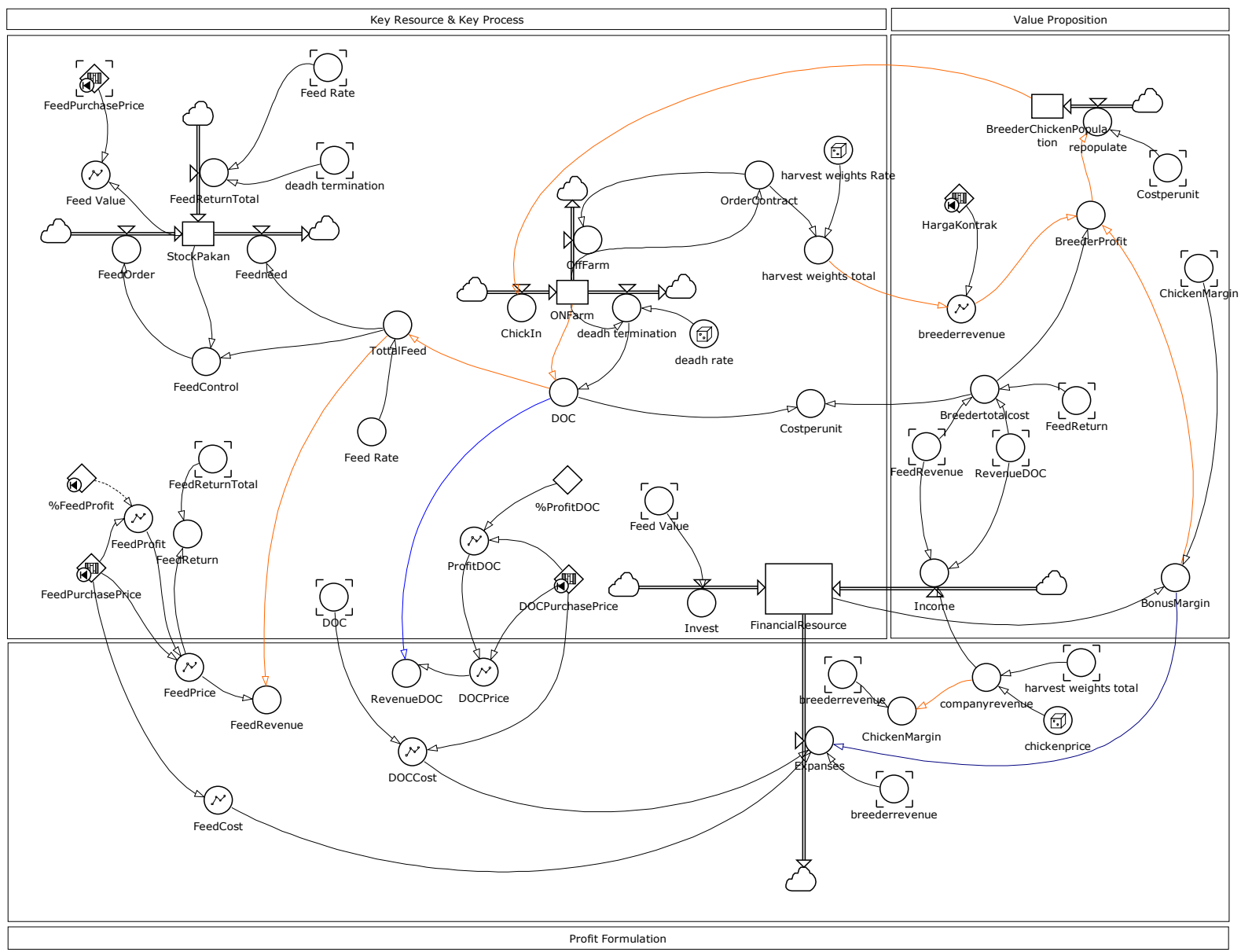

Figure 2 - Dynamic Business model of PT.AMM

In this phase, only the livestock process is not optimized to avoid crop failure so that the livestock population is lowered only to meet local needs. A good relationship with the supplier in the contract purchase agreement allows the purchase of a number of suggestions 
for livestock production not limited provided the payment is paid at a certain period accordingly so that the supplier factor is not included in the model.

Based on the data collected, stock and flow can be arranged which can be seen in the stock and flow illustrated in figure 2 that represent dependencies and relationship patterns for each indicator. There are 2 types of loops in a system dynamic, namely reinforcing loop and balancing loop. Reinforcing loops give a positive relationship pattern where if one or more indicators increase, while the loop balancing has a reverse pattern of relationships. There are 3 Reinforcing loops and 3 balancing loops in the model.

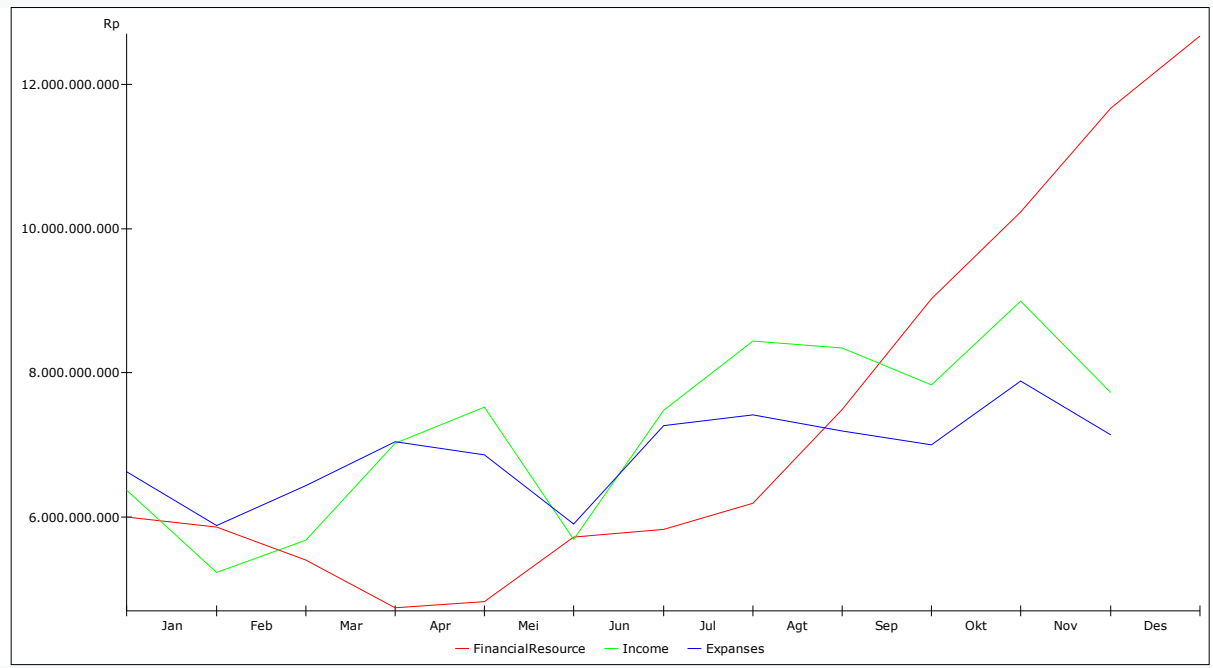

Figure 3 - Financial Resource, Income \& Expenses simulation

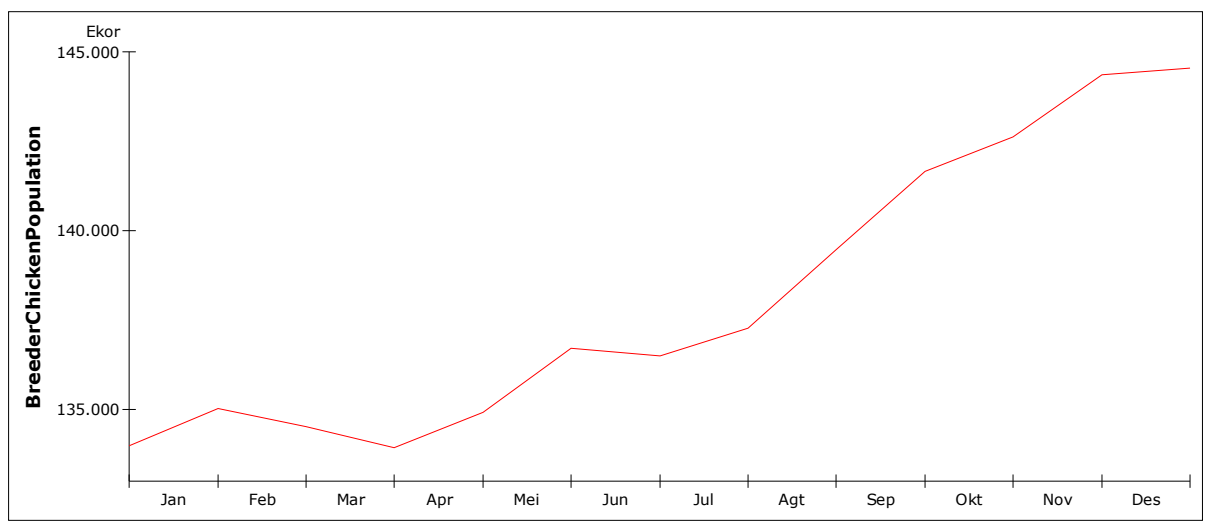

Figure 4 - Breeder Chicken Population Simulation

Table 2 - Income, expanse and financial resource simulation

\begin{tabular}{|c|c|c|c|c|c|}
\hline \multicolumn{6}{|c|}{ (Rp) } \\
\hline Time & FinancialResource & Income & Expanses & Breedertotalcost & Invest \\
\hline 01 Jan 2019 & $6.000 .000 .000,00$ & $6.413 .238 .510,42$ & $6.656 .777 .452,98$ & $3.372 .354 .396,18$ & $107.985 .000,00$ \\
\hline 01 Feb 2019 & $5.864 .446 .057,44$ & $5.310 .501 .863,74$ & $5.946 .742 .809,95$ & $3.309 .119 .467,23$ & $200.805 .698,04$ \\
\hline 01 Mar 2019 & $5.429 .010 .809,26$ & $5.818 .408 .360,43$ & $6.549 .762 .821,99$ & $3.578 .556 .336,06$ & $90.408 .748,23$ \\
\hline 01 Apr 2019 & $4.788 .065 .095,93$ & $7.192 .266 .082,54$ & 7.184.463.325,22 & $3.632 .184 .178,19$ & $109.907 .604,28$ \\
\hline 01 Mei 2019 & $4.905 .775 .457,54$ & $7.702 .437 .398,77$ & $7.012 .607 .863,71$ & $3.470 .599 .899,12$ & $253.458 .982,69$ \\
\hline 01 Jun 2019 & $5.849 .063 .975,28$ & $5.827 .413 .983,22$ & $5.995 .750 .328,99$ & $3.326 .246 .350,35$ & $321.128 .667,37$ \\
\hline 01 Jul 2019 & $6.001 .856 .296,89$ & $7.678 .830 .950,07$ & $7.417 .289 .886,65$ & $3.787 .291 .815,31$ & $156.685 .297,24$ \\
\hline 01 Agt 2019 & $6.420 .082 .657,55$ & $8.634 .527 .283,25$ & $7.570 .332 .179,70$ & $3.692 .943 .981,36$ & $291.126 .502,90$ \\
\hline 01 Sep 2019 & $7.775 .404 .264,01$ & $8.467 .198 .764,49$ & $7.268 .903 .216,96$ & $3.583 .585 .848,88$ & $394.726 .933,91$ \\
\hline 01 Okt 2019 & $9.368 .426 .745,45$ & $7.884 .078 .775,46$ & $7.001 .450 .563,86$ & $3.639 .810 .971,82$ & $395.751 .678,68$ \\
\hline 01 Nov 2019 & $10.646 .806 .635,73$ & $8.966 .191 .150,03$ & 7.823.038.953,91 & $3.896 .058 .001,76$ & $340.170 .005,65$ \\
\hline 01 Des 2019 & $12.130 .128 .837,50$ & 7.667.148.377,79 & 7.008.975.115,68 & $3.778 .588 .005,22$ & 414.424.178,94 \\
\hline 01 Jan 2020 & $13.202 .726 .278,54$ & $?$ & ? & $?$ & ? \\
\hline & & & & & \\
\hline & & & & & \\
\hline
\end{tabular}


Table 3 - Breeder Profit \& Margin Bonus Simulation

\begin{tabular}{|c|r|r|}
\hline \multicolumn{3}{|c|}{ (Rp) } \\
\hline Time & \multicolumn{1}{|c|}{ BreederProfit } & \multicolumn{1}{|c|}{ BonusMargin } \\
\hline 01 Jan 2019 & $259.898 .268,70$ & 0,00 \\
\hline 01 Feb 2019 & $(129.125 .972,18)$ & 0,00 \\
\hline 01 Mar 2019 & $(159.778 .336,95)$ & 0,00 \\
\hline 01 Apr 2019 & $252.756 .456,58$ & 0,00 \\
\hline 01 Mei 2019 & $456.031 .408,67$ & 0,00 \\
\hline 01 Jun 2019 & $(55.651 .070,52)$ & 0,00 \\
\hline 01 Jul 2019 & $203.733 .104,23$ & 0,00 \\
\hline 01 Agt 2019 & $566.796 .638,42$ & $99.776 .096,24$ \\
\hline 01 Sep 2019 & $573.328 .118,64$ & $118.954 .794,05$ \\
\hline 01 Okt 2019 & $255.496 .805,43$ & 0,00 \\
\hline 01 Nov 2019 & $466.232 .910,38$ & $99.790 .492,86$ \\
\hline 01 Des 2019 & $53.810 .563,87$ & 0,00 \\
\hline 01 Jan 2020 & $?$ & $?$ \\
\hline & \multicolumn{2}{|c|}{} \\
\hline & \multicolumn{3}{|c|}{} \\
\hline
\end{tabular}

The initial value of the purchase price of feed is $\mathrm{Rp} .7100$ and the purchase price of DOC is Rp.5300 and simulated an increase of $4 \%$ each month. The assumption of the increase is based on the observation of the last 3 years. Death rates, harvest weights, market prices are random. While financial resources, breeders population, on farm population and feedstock at the beginning of each simulation were valued at IDR $6,000,000,000,13,384$ chickens, 125,000 chickens, and 15,000 kg.

12-month time simulations show the company cumulatively has financial resources of IDR $13,212,235,506.54$ from the initial period of IDR $6,000,000,000$ or an increase of $120 \%$. And the breeders' population cumulatively increased from 133928 to 144375 at the end of the simulation period.

Table 4 - Resource Configuration Simulation and PT AMM Production Results

\begin{tabular}{|c|c|c|c|c|c|c|c|c|c|}
\hline Time & Mei 19 & Jun 19 & Jul 19 & Agt 19 & Sep 19 & Okt 19 & Nov 19 & Des 19 & $\operatorname{Jan} 20$ \\
\hline BreederChickenPopulation (First) (Ekor) & $134.919,89$ & $136.729,39$ & $136.519,22$ & $137.293,82$ & $139.472,02$ & $141.664,95$ & $142.622,03$ & $144.363,13$ & $144.558,10$ \\
\hline TottalFeed (First) (Kg) & $337.390,44$ & $307.760,62$ & $352.787,23$ & $347.702,76$ & $335.820,14$ & $334.046,81$ & $356.461,33$ & $335.417,54$ & $354.948,82$ \\
\hline FeedOrder (First) (Kg) & $302.887,45$ & $263.992,23$ & $331.811,95$ & $308.927,25$ & $283.813,96$ & $282.590,34$ & $312.664,50$ & $282.238,51$ & $315.776,22$ \\
\hline DOC (First) (Ekor) & $137.710,39$ & $125.616,58$ & 143.994,79 & $141.919,49$ & $137.069,45$ & $136.345,63$ & $145.494,42$ & $136.905,12$ & $144.877,07$ \\
\hline StockPakan (First) (Kg) & $34.502,99$ & $43.768,39$ & $20.975,27$ & $38.775,51$ & $52.006,18$ & $51.456,47$ & 43.796,83 & $53.179,03$ & $39.172,59$ \\
\hline FeedReturnTotal (First) (Kg) & $43.768,39$ & $20.975,27$ & $38.775,51$ & $52.006,18$ & $51.456,47$ & $43.796,83$ & $53.179,03$ & $39.172,59$ & $40.431,74$ \\
\hline deadh rate (First) (\%) & 14,91 & 7,31 & 12,35 & 17,59 & 18,10 & 15,09 & 17,53 & 13,22 & 12,86 \\
\hline harvest weights total (First) (Kg) & $218.146,18$ & $181.699,74$ & $221.723,61$ & $231.109,14$ & $224.331,07$ & $216.405,99$ & $236.805,58$ & $212.911,03$ & $224.376,47$ \\
\hline DOCPurchasePrice (Rp/Ekor) & $6.252,00$ & $6.275,00$ & $6.581,00$ & $6.984,00$ & $6.988,00$ & $6.841,00$ & $7.095,00$ & $7.137,00$ & \\
\hline FeedPurchasePrice (Rp/Kg) & $7.346,00$ & $7.337,00$ & $7.470,00$ & $7.508,00$ & $7.590,00$ & $7.691,00$ & $7.767,00$ & $7.793,00$ & \\
\hline FinancialResource (First) (Rp) & $4.905 .775 .457,54$ & $5.849 .063 .975,28$ & $6.001 .856 .296,89$ & $6.420 .082 .657,55$ & $7.775 .404 .264,01$ & $9.368 .426 .745,45$ & 10.646.806.635,73 & $12.130 .128 .837,50 \mid$ & 13.202.726.278,54 \\
\hline
\end{tabular}

The optimal configuration of all business model components for the company in the simulation is seen in May - December with a positive cumulative increase. If it reflects the vision of a company that wants balanced profits for both the company and the farmer. The exact configuration is in August, September and November of the simulation month. This is because the farmer reaches the maximum profit value and the company has a positive profit. The detailed optimal configuration can be seen in table 4 .

\section{CONCLUSION}

The simulation results show that in January to March, and the month of production costs are higher than income and then the company calculates it as production debt to the related supplier. Relationships that are well established with suppliers allow payments in stages or are repaid in the second and fourth quarters. But this will endanger the company if these conditions occur in succession so that the company cannot pay its production debt, the result of which will affect the supplier's trust. Suggestions for companies based on the results of the analysis include limiting the population if the company experiences losses based on production costs in the previous period so that the company can control production costs in 
accordance with its financial resources. Then for writers or researchers who conduct similar research to add variables that link financial resources with production costs so that there is a calculation of livestock production population that is in accordance with the ability of the company if the company's financial resources are negative. Conversely, if financial resources are positive, the company accommodates the ability of the breeders population to achieve maximum profit.

The author is aware of the limitations of this study, as for the limitations of the study's including:

- Limiting the scope of the study by eliminating external factors that affect market prices and demand for broiler products, this is due to the limitations of data and information and time in completing this study. Among them are the number of farmer populations, the number of similar imported products, or other substitute products such as beef;

- Limiting the company's resources to be limited to livestock production facilities even though human resources must also be included in the variables in the simulation model. This is because, PT. AMM is a family company that allows employees to be recruited and dismissed based on family principles. the termination simulation and the contribution of HR in this case are concerned to interfere with the overall simulation so the authors chose to negate the variable;

- Eliminate the contribution of human resources and resources for livestock production facilities to the level of productivity of production. The relationship between the quality of livestock production facilities and the contribution of farmers is eliminated given the limitations of the authors in interpreting them because the study is included in the field of animal husbandry study so it is good if researchers with related competencies can make simulations on this matter.

\section{REFERENCES}

1. Cosenz, F., \& Noto, G. (2018). A Dynamic Business Modelling Approach to desagn and experiment new business venture strategis. 127-140.

2. Davis, J., Eisenhardt, K., \& Bingham, C. (2007). Developing Theory Through Simulation Methods. Acadamy of Management Review.

3. Forester. (1997). Industrial Dynamics. Journal of the operational research sociaty, 10371043. doi: https: //doi.org/10.1057/palgrave.jors.2600946.

4. Fransen, J. (2013, mart). Innovation in SMEs. The case of home accessories in Yogyakarta, Indonesia. The Netherlands: Institute For Housing and Urban Development Studies.

5. Geissdoerfer, M., Savaget, P., \& Evans , S. (2017). The Cambridge Business Model Innovation Process. 14th Global Conference on Sustainable Manufacturing (pp. 262 269). Stellenbosch: Procedia Manufacturing.

6. Geissdoerfer, M., Vladimirova, D., \& Evans, S. (2018). Sustainable business model innovation: A review. Journal of Cleaner Production, 401-416.

7. Jhon.WCreswell. (2010). Research Design, Pendekatan Kualitatif, Kuantitatif, and Mixed. Jakarta: Pustaka Pelajar.

8. Jhonson, M. W. (2018). Reinvent Your Business Model. Boston, massachusets: Harvard Business review.

9. Masanell, R. (2010). From strategy to business models and onto tactics. 43.

10. Morecroft, J. D. (2015). Strategic Modelling and Business Dynamics: A feedback systems approach. Wiley.

11. Richardson, J. (2008). The business model: an integrative framework for strategy execution. 17, 133-144. doi: 10.1002/jsc.821.

12. Sterman (2001). System dynamics modeling: Tools for learning in a complex world. 43.

13. Zhao, X., Bon-GangHwang, \& Lu, Q. (2018). Typology of business model innovations for delivering zero carbon buildings. 198, 1213-1226. 